\title{
Pembrolizumab for the treatment of patients with recurrent locally advanced or metastatic gastric or gastroesophageal junction cancer: an evidence- based review of place in therapy
}

This article was published in the following Dove Press journal:

OncoTargets and Therapy

\author{
Rutika Mehta' \\ Anand Shah ${ }^{2}$ \\ Khaldoun Almhanna ${ }^{3}$ \\ 'Department of Gastrointestinal \\ Oncology, Moffitt Cancer Center, \\ Tampa, FL 336/2, USA; ${ }^{2}$ Department \\ of Pharmacy, Moffitt Cancer Center, \\ Tampa, FL 336/2, USA; ${ }^{3}$ Department \\ of Hematology/Oncology, Lifespan \\ Cancer Institute, Providence, RI, USA
}

\begin{abstract}
Gastric and esopahgeal cancers account for the six most common causes of cancer death worldwide. Locally advanced resectable cancers have a 5-year life expectancy of $30 \%$. Despite use of chemotherapy, median overall survival for stage IV cancer rarely exceeds 1 year. A subset of gastric cancers such as microsatellite-instable tumor and Epstein-Barr virus-positive tumors have a rich immune infiltrate that makes them more responsive to immune-directed therapies. Tumors can evade T-cell-mediated "immune surveillance" by activating the programmed cell death receptor 1 (PD-1)/programmed death ligand 1 (PD-L1) pathway. Targeting PD-1 and thus de-engaging them from its ligands can help restore immunogenicity. Pembrolizumab is the first immunotherapy to be approved by US FDA for PD-L1 expressing gastric and gastroesopahgeal junction (GEJ) cancers after they have progressed on at least two prior lines of treatment. While PD-L1 positivity does not define tumor's responsiveness to pembrolizumab, PD-L1-positive tumors have better overall response rates. The treatment is usually well tolerated and has a favorable adverse events profile. The exact setting for use of pembrolizumab remains to be determined. Pembrolizumab failed to improve overall survival when administered as second-line treatment for advanced, metastatic gastric and GEJ cancers. There are several ongoing studies with various combinations and different settings not only with pembrolizumab but also with other checkpoint inhibitors.
\end{abstract}

Keywords: gastric cancer, gastroesophageal junction cancer, pembrolizumab, PD-1

\section{Introduction}

Gastric and esophageal cancers are the fifth and eighth most common cancers occurring worldwide, respectively. They are also among the top six cancers for mortality, accounting for over 1.1 million deaths worldwide in 2012. ${ }^{1}$ In the US alone, a little over 43,000 new cases and 26,650 deaths are expected to occur due to gastric and esophageal cancers in 2018. ${ }^{2}$ There is significant geographical variation in the incidence of gastric and gastroesophageal junction (GEJ) cancers worldwide. The incidence rates of gastric cancers are highest in parts of Eastern Europe, Iran, Russia, many parts of Central and South America, and several countries of East Asia. ${ }^{1}$ Gastric adenocarcinoma accounts for the most common histological subtype of gastric cancers $(\sim 95 \%)$, others being lymphomas, neuroendocrine tumors, and mesenchymal tumors. ${ }^{1,3}$ Adenocarcinomas are the most common histological subtype of GEJ cancers (90\%). In the US, the incidence of noncardia gastric cancers have declined significantly over the past four decades. However, during this same time, the incidence of GEJ adenocarcinomas (GEJAC)
Correspondence: Khaldoun Almhann Department of Hematology/Oncology, Lifespan Cancer Institute, 593 Eddy St, Providence, RI 02903, USA

Tel + I 40I 4445396

Fax + I 40I 4448918

Email kalmhanna@lifespan.org 
has steadily increased. These are four times as common in Whites than in Blacks and also more common among males than among females. ${ }^{4}$ The rise in the incidence of GEJAC is being attributed to increased incidence of gastroesophageal reflux disease and obesity. ${ }^{5}$ In spite of improvements in multidisciplinary diagnostic and treatment modalities, the prognosis of GEJ and gastric cancers remains poor. While localized disease achieves 5-year survival rates of $45 \%$ and $68 \%$ in esophageal and gastric cancers, respectively, the 5-year survival rates for advanced disease with either cancers approach only $\sim 5 \%{ }^{2}$

Combination of platinum compounds such as cisplatin or oxaliplatin with fluoropyrimidines such as 5-fluorouracil (5-FU) or capecitabine remains the mainstay of standard first-line therapy for gastric cancer improving overall survival (OS) to about 9-11 months. ${ }^{6-8}$ Therefore, there is a need for targeted treatments and pathway-driven treatments for advanced gastric cancer. The first targeted therapy to be approved for gastric cancer was trastuzumab based on significant improvement in OS from 11 months to 13.8 months $(P=0.046)$ with the addition of trastuzumab to 5-FU and cisplatin as first-line treatment in patients with advanced cancer whose cancer overexpressed HER-2neu. ${ }^{9}$ The next targeted therapy to be approved for gastric cancer was ramucirumab, which was initially given as single agent in April 2014 and then in combination with paclitaxel in November 2014 after the success of two landmark trials REGARD and RAINBOW that demonstrated improvement in OS of gastric cancer patients who have previously been treated with a fluoropyrimidine-based therapy. Ramucirumab showed an absolute OS benefit of 1.3 months over placebo as single agent and 2.2 months in combination with paclitaxel over paclitaxel alone, with OS benefit being statistically significant in both studies. ${ }^{10,11}$ Other treatments directed against HER-2neu overexpression, mesenchymal epithelial transition factor, epidermal growth factor receptor, and vascular endothelial growth factor have not shown improvement in OS in gastric cancer patients across several trials. ${ }^{12-19}$

In a recent molecular classification performed by The Cancer Genome Atlas (TCGA), four subtypes have been proposed. ${ }^{20}$ Although correlation to clinical data was not made and therefore prognostic differences cannot be ascertained, some gastric cancers were distinctly found to have multiple DNA alterations that might result in increased neoantigens (mismatch repair deficiency or microsatellite instability-high [MSI-H]) and as such sensitive to immune modulators such as checkpoint inhibitors. In recent years, emergence of immune-checkpoint inhibitors has revolutionized the management of solid tumors. Checkpoint inhibitors targeting programmed cell death receptor 1 (PD-1), programmed death ligand 1 (PD-L1), and cytotoxic T-lymphocyte associated protein 4 (CTLA-4) have led to improved response rates and OS across several tumor types. In many cases, these responses are characterized by their durability and a favorable adverse effect profile. In September 2017, the US FDA approved pembrolizumab (Merck \& Co., Kenilworth, NJ, USA) for the third-line treatment of advanced PD-L1-positive GEJ tumor. ${ }^{21}$ This approval was based upon tumor response rates and durability of response as reported in the KEYNOTE-059 Phase II trial. ${ }^{22}$ This review will discuss the pharmacology, safety, and efficacy of pembrolizumab in the treatment of gastric and GEJ tumors.

\section{Immune landscape of gastric and GEJ cancers}

The mechanism by which cancer cells including gastric and GEJ cancers are kept in check and prevented from developing is called "immune surveillance", whereby the immune cells destroy cancer cells after recognition of tumor-specific antigens, before they can cause harm. If this elimination is incomplete, there is a state of equilibrium during which time the tumor may develop and accumulate DNA mutations or remain dormant. If the immune system is yet not able to completely eliminate the tumor cells, then this mechanism is called "immune escape". Activated cytotoxic T cells (CTLs) assist in immune surveillance. Tumor infiltrating lymphocytes (TILs) when found such as in colon and gastric cancers portend a good prognosis. TILs by utilizing perforins and granzymes kill tumor cells via direct and indirect mechanisms. The tumor microenvironment has immunosuppressive network that exhausts the CTL/TIL leading to T-cell dysfunction. The antigen recognition by CTLs induced PD-1 expression and upon interaction with its ligand, programmed death ligand-1 (PD-L1), T-cell function is inhibited and is proposed as one of the mechanisms of "immune escape" by cancer. ${ }^{5,23}$

TCGA performed a comprehensive analysis of 295 primary tumor samples from patients with untreated gastric adenocarcinoma, using whole-exome sequencing, somatic copy number analysis, DNA methylation profiling, mRNA sequencing, microRNA sequencing, and reverse phase protein array. The four molecular subtypes identified were as follows: 1) Epstein-Barr virus (EBV)-positive $(9 \%), 2)$ microsatellite instability-high (MSI-H) (22\%), 3 ) genomically stable (20\%), and 4) chromosomal instability (CIN) $(50 \%) .{ }^{20}$ The EBV-positive tumors showed a high frequency of DNA hypermethylation as well as amplifications of JAK-2, PD-L1, and PD-L2. Unlike the EBV-positive 
tumors, the MSI-H tumors have $M L H 1$ silencing as a result of methylation. ${ }^{20}$ About $40 \%$ of gastric and GEJ cancers are PD-L1 positive. PD-L1 positivity is more frequent in EBVpositive and MSI-H tumors. ${ }^{5}$ Among EBV-positive cancers, PD-L1 staining is observed not only in $50 \%$ of tumor cells but also in $94 \%$ of infiltrating immune cells. Similarly, among MSI-H tumors, $33 \%$ and $45 \%$ of tumor cells and immune cells are stained positive for PD-L1, respectively. Thus, both these subtypes of gastric cancers are considered to have a rich immune infiltrate and therefore more responsive to checkpoint inhibitors. $^{24}$

Studies have shown that tumors with frequent somatic mutations have higher immune signatures than tumors with lower somatic mutations but high copy number alterations. These low immune signature cancers also correlated with CIN. Some high immune signature cancers include lung adenocarcinoma, melanoma, or kidney cancer, all of which have shown superior responses to immunotherapy. As noted above, a majority of gastric cancers are $\mathrm{CIN}$ which correlates with low immune signatures and possibly lower responses to immunotherapeutic agents. ${ }^{25}$

\section{Pembrolizumab in gastric and GEJ cancers}

\section{Pharmacology and mechanism of action}

Pembrolizumab (Keytruda ${ }^{\circledR}$; MK-3745) is a humanized, highly selective IgG 4 kappa isotype monoclonal antibody against PD-1. ${ }^{21}$ Its molecular weight is $149 \mathrm{kDa}$. As outlined earlier, PD-1 is expressed in activated T cells, while its ligands PD-L1 and PD-L2 are frequently overexpressed in some tumors. When PD-1 engages with its ligands on tumor cells, the activated pathways send inhibitory signals to T cells, thus disrupting its function of immune surveillance and in turn promote tumor growth. Pembrolizumab, by binding to PD-1, prevents its interaction with PD-1 ligands, thus releasing the inhibitory response of the immune response (Figure 1). ${ }^{26}$

\section{Pharmacokinetics}

Pembrolizumab is a fully humanized IgG monoclonal antibody; therefore, it follows pharmacokinetics (PK) similar to that of endogenous IgG. ${ }^{27}$ Its volume of distribution (VD) is $6 \mathrm{~L}$, which is similar to that of plasma volume. Despite the small VD, pembrolizumab is distributed to peripheral tissues by paracellular and/or transcellular movement following parenteral dosing. The drug is eliminated by both targetmediated (linear) and constant region-mediated (nonlinear) routes. ${ }^{27}$ Terminal half-life is 22 days. ${ }^{21}$ A recent study evaluated population-based PK of pembrolizumab at various doses. This included patients receiving pembrolizumab

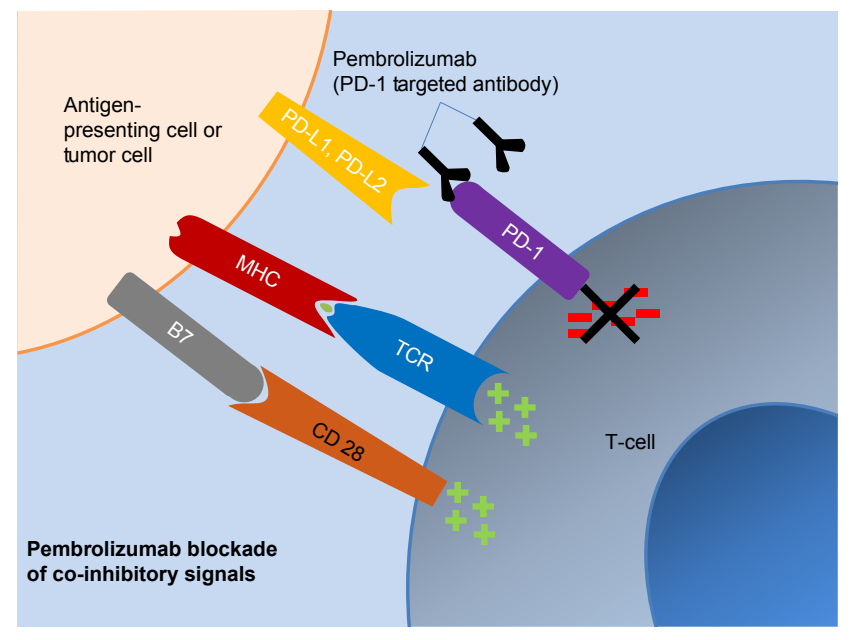

Figure I Pharmacologic action of pembrolizumab.

Abbreviations: $\mathrm{MH}$; major histocompatibility complex; PD-LI, programmed death ligand-I; PD-L2, programmed death ligand-2; TCR, T cell receptor.

$2 \mathrm{mg} / \mathrm{kg}$ every 3 weeks, $10 \mathrm{mg} / \mathrm{kg}$ every 2 weeks and 3 weeks as well as $200 \mathrm{mg}$ flat dose every 3 weeks. ${ }^{28}$ This study found that weight-based dose and fixed dose were appropriate for pembrolizumab and neither regimen provided a PK advantage over the other. ${ }^{28}$ Pembrolizumab does not require dose adjustment for mild, moderate, or severe renal impairment and mild hepatic impairment. There is insufficient data to determine whether pembrolizumab clearance is impacted in a clinically meaningful way in patients with moderate to severe hepatic impairment. In addition, age, sex, and race do not have clinically important effects on pembrolizumab clearance. $^{21}$

\section{Clinical studies}

The very first indication of efficacy of checkpoint inhibitors in MSI-H advanced cancers refractory to prior systemic treatment was demonstrated in a Phase II clinical trial led by Le et al (NCT01876511). Eighty-six patients with MSI-H colorectal cancers (CRC) and MSI-H non-CRCs including five patients with gastroesophageal cancers were enrolled. Pembrolizumab $10 \mathrm{mg} / \mathrm{kg}$ of body weight was administered intravenously every 14 days. The objective response rate (ORR) in MSI-H gastroesophageal tumors was 60\% similar to that observed for CRC (52\%), with three of the five patients achieving complete response (CR). ${ }^{29,30}$

Two Phase Ib studies of single agent pembrolizumab in advanced solid tumors have provided us with safety data in previously treated PD-L1-positive advanced or metastatic cancers. $^{31,32}$

\section{KEYNOTE-0I 2}

This is a multicenter, open-label, Phase Ib study of single agent pembrolizumab that included patients with advanced 
or metastatic gastric cancer, urothelial cancer, triple-negative breast cancer, and head and neck cancer. The gastric cancer cohort included recurrent or metastatic PD-L1-positive gastric or GEJ adenocarcinomas with no limit on number of prior treatment. Positivity was defined as $>1 \%$ of tumor and/ or contiguous mononuclear inflammatory cells (using Dako Assay, 22C3 antibody). Thirty-nine patients from centers across USA, Japan, Israel, South Korea, and Taiwan were included in the gastric cohort with similar numbers from Asia vs rest of the world. Patients received pembrolizumab at $10 \mathrm{mg} / \mathrm{kg}$ intravenously every 2 weeks. The median age was 63 years with majority (72\%) being males. Four (10\%) patients were treatment naïve, while $67 \%$ had received two or more prior lines of systemic treatment. Of the 24 patients for whom MSI status was available, 4 (17\%) were noted to be MSI-H. The median follow-up duration was 10.8 months with $85 \%$ (33 patients) discontinuing treatment (32 due to progressive disease and 1 due to treatment-related adverse events [AEs]). Thirty-six patients were evaluable for response and the confirmed ORR was 22\% [95\% CI 10-39] (eight patients). There were no CRs. Time to response was 2 months, with median duration of response being 9.2 months. The median progression-free survival (PFS) was 1.9 months (95\% CI 1.8-3.5) and median OS was 11.4 months $(95 \%$ CI 5.7-not reached). In terms of PD-L1 positivity, patients were evaluated for PD-L1 staining based on the previously developed prototype assay at the time of screening and then based on the clinical trial assay as well. Unfortunately, discordant results were noted between these two PD-L1 tests. Interestingly, based on tumor proportion score (TPS), tumors with TPS of 0 has $24 \%$ ORR and tumors with TPS $\geq 1$ had $17 \%$ ORR. $^{32}$

\section{KEYNOTE-028}

This is a non-randomized, multi-center, open-label, Phase Ib study of single agent pembrolizumab including PD-L1positive 20 different tumor subtypes that enrolled patients from USA, UK, France, Japan, Korea, and Taiwan. Twentythree patients with esophageal cancer were included in the study. Patients were treated with pembrolizumab at $10 \mathrm{mg} / \mathrm{kg}$ intravenously every 2 weeks up to 2 years. The median age was 65 years, majority were men (83\%), and 78\% were of squamous cell histology. More than half had received prior radiation treatment and $87 \%$ had received two or more prior lines of treatment. The median duration of follow-up was 7 months and majority (91\%) had treatment discontinuation due to progressive disease $(57 \%)$ or AEs $(9 \%)$. The ORR was $30 \%$ (95\% CI 13\%-53\%). The ORR for adenocarcinomas was superior (40\%) than that for squamous cell carcinomas (28\%). Median time to response was 4 months, with duration of response being 15 months. The median PFS was 1.8 months (95\% CI 1.7-2.9 months) and median OS was 7 months (95\% CI 4.3-17.7 months). ${ }^{31}$

In both studies, KEYNOTE-012 and KEYNOTE-028, a six-gene (CXCL9, CXCL10,IDO1, IFNG, HLA-DRA, and $S T A T)$ interferon $\gamma$-related signature was evaluated and correlated with ORR and PFS. However, in both these studies, the gene signature could not predict the response for pembrolizumab in these cohorts.

\section{KEYNOTE-059}

KEYNOTE-059, a Phase II, multicohort, single-arm trial for treatment of advanced gastric and GEJ cancers with pembrolizumab as monotherapy or in combination with chemotherapy has completed enrollment. The first cohort included patients with advanced or metastatic gastric and GEJ cancers who had received at least two prior systemic therapies and were treated with pembrolizumab $200 \mathrm{mg}$ every 3 weeks. Cohort 2 assessed the combination of pembrolizumab 200 mg every 3 weeks in combination with 5-FU and cisplatin as first-line treatment for advanced gastric and GEJ cancers, while cohort 3 assessed pembrolizumab monotherapy as first-line treatment in the same population. Cohort 3 included only PD-L1-positive tumors. The PD-L1 positivity rates were $57 \%$ and $64 \%$ in cohorts 1 and 2 , respectively.

Cohort 1 enrolled 259 patients with recurrent or metastatic gastric or GEJ adenocarcinomas across 16 countries irrespective of PD-L1 status. The median age was 62 years with majority being males (76.4\%). Fifty-two percent patients had received two or more prior therapies for metastatic disease. More than half of the patients $(57.1 \%)$ were PD-L1 positive. The median duration of follow-up was 5.8 months, with about $90 \%$ discontinued treatment mostly due to progressive disease. The ORR was $11.6 \%$ (95\% CI 8.0\%-16.1\%) with CR in $2.3 \%(95 \%$ CI $0.9 \%-5.0 \%)$ of the entire study population. Median time to response was 2.1 months, with median duration of response being 8.4 months. Median PFS was 2.0 months (95\% CI 2.0-2.1) and median OS was 5.6 months (95\% CI 4.3-6.9). Among PD-L1-positive tumors, ORR was $15.5 \%$ as compared to $6.4 \%$ in PD-L1-negative tumors. Response rates were superior when pembrolizumab was used as third-line treatment as compared to that when used as fourth or further line of treatment (16.4\% vs 6.4\%). Seven of the evaluable tumors were MSI-H and the ORR was $57.1 \%$ as compared to non-MSI-H tumors $(9.0 \%) .{ }^{33}$ Based on this favorable data and good response rates in third-line 
setting, US FDA approved the use of pembrolizumab in PDL1-positive gastric and GEJ adenocarcinomas after progression on two prior lines of treatment in September 2017. ${ }^{34}$

Cohort 2 with HER-2neu-negative advanced gastric and GEJ adenocarcinoma patients treated with pembrolizumab in combination with 5-FU and cisplatin as first-line treatment enrolled 25 patients. The median age was 64 years with $64 \%$ males. While in cohort 1 , GEJ and gastric cancer cases were balanced, cohort 2 had a majority of gastric adenocarcinomas (80\%). PD-L1 positivity rate was $64 \%$. The ORR was $60 \%$ (95\% CI 39\%-79\%) with $4 \%$ CR (95\% CI $0 \%-20 \%)$. In PD-L1-positive patients, the ORR was $68.8 \%$ (95\% CI $41 \%-89 \%)$, while it was $37.5 \%$ (95\% CI 9\%-76\%) in PD-L1-negative patients. ${ }^{35}$ The CR rate was $0 \%$ (95\% CI 0\%-22\%) and $13 \%$ (95\% CI 0\%-53\%) in PDL1-positive and PD-L1-negative patients, respectively. The median follow-up was 13.8 months, with duration of response being 4.6 months. The median PFS was 6.5 months $(95 \%$ CI 5.9-10.6 months) and median OS was 13.8 months (95\% CI 8.6 months-not reached). These encouraging results have led to the conception of Phase III trial KEYNOTE-062 that is currently ongoing.

Preliminary results from cohort 3 were presented at European Society for Medical Oncology 2017. Thirtyone patients were enrolled with median age 62 years and more than half $(61 \%)$ being male patients. The majority were gastric adenocarcinomas $(61 \%)$ and all patients were HER-2neu negative and PD-L1 negative. The ORR for this cohort was $25.8 \%$ (95\% CI $12 \%-45 \%)$ with $7 \%$ CR $(95 \%$ CI 1\%-21\%). The median follow-up was 17.5 months and duration of response was 9.6 months. The median PFS was 3.3 months (2.0-6.0 months) and median OS was 20.7 months (9.2-20.7 months). ${ }^{36}$

\section{Other studies}

A Phase III randomized, open-label clinical trial (KEYNOTE061) assessing single agent pembrolizumab vs paclitaxel in PD-L1-positive advanced, metastatic gastric and GEJ adenocarcinomas (including HER-2-neu positive) after progression on first-line fluoropyrimidine and platinum doublet, failed to show OS benefit as second-line treatment in this population (HR, 0.82 [95\% CI, 0.66-1.03]; $P=0.042$ [one-sided]). ${ }^{37,38}$ To assess the efficacy of pembrolizumab as first-line treatment in PD-L1+/HER-2neu-negative locally advanced or metastatic gastric or GEJ adenocarcinomas, a Phase III trial (KEYNOTE-062) is currently enrolling patients in a 1:1:1 fashion to pembrolizumab monotherapy vs pembrolizumab plus 5-FU/cisplatin vs placebo plus 5-FU/cisplatin. ${ }^{39}$
Details about the characteristics and primary outcome measures of these studies are outlined in Tables 1 and 2.

\section{Safety and tolerability}

Safety of pembrolizumab in gastric and esophageal tumors has been evaluated in three studies as shown in Tables 1 and 2 . Overall toxicity profile in gastric and esophageal tumors was similar to that seen in previously published studies in other advanced malignancies. ${ }^{40-42}$ Treatment interruptions and discontinuations occurred at higher rates in patients receiving $10 \mathrm{mg} / \mathrm{kg}$ dose than in those receiving $200 \mathrm{mg}$ flat dose. Details of treatment-related AEs are outlined in Table 3.

The immune-related AEs (nine patients, 23\%) noted in KEYNOTE-012 were mostly grade 1 or grade 2 thyroid disorders (hypothyroidism or hyperthyroidism) and also one grade 4 pneumonitis. ${ }^{32}$ In KEYNOTE-028, the immune-related AEs were noted in six patients $(26 \%)$ and included hypothyroidism, enterocolitis, adrenal insufficiency, generalized rash, and hyperthyroidism. ${ }^{31}$ In cohort 1 of KEYNOTE-059 study, 46 patients (17.8\%) experienced immune-related AEs, most commonly being hypothyroidism, hyperthyroidism, and colitis. Ten patients $(21.7 \%)$ had their treatment interrupted because of immune-related AEs. All patients in cohort 2 of KEYNOTE-059 experienced immunemediated or infusion-related AEs, common ones being hyperthyroidism, hypothyroidism, and rash. Twenty-five (80\%) patients in cohort 3 developed immune-related AEs, common ones being pneumonitis, colitis, and rash. There was one death attributed to pneumonitis in this study. $33,35,36$

\section{Quality of life (QoL) and cost-effectiveness}

While long-term assessments on QoL with pembrolizumab treatment have not been made in specific gastric and GEJ adenocarcinoma population, some studies have focused on non-small-cell lung cancer (NSCLC) and urothelial cancer, favoring treatment with pembrolizumab as compared to chemotherapy. Analyses of KEYNOTE-042, a Phase III trial of pembrolizumab vs platinum doublet chemotherapy in treatment-naïve NSCLC patients, showed that baseline-toweek 15 change in European Organization for the Research and Treatment of Cancer (EORTC) Quality of Life Questionnaire Core 30 items (QLQ-C30) Global Health Status (GHS)/ QoLscore was 6.9 (95\% CI 3.3-10.6) for pembrolizumab and -0.9 ( -4.8 to 3.0) for chemotherapy, for a difference of 7.8 (2.9-12.8; two-sided nominal $P=0.0020$ ). Time to deterioration (TTD) was also significantly longer with pembrolizumab than with chemotherapy. ${ }^{43}$ A Health-related Quality of Life (HRQoL) analysis of KEYNOTE-045 study comparing 


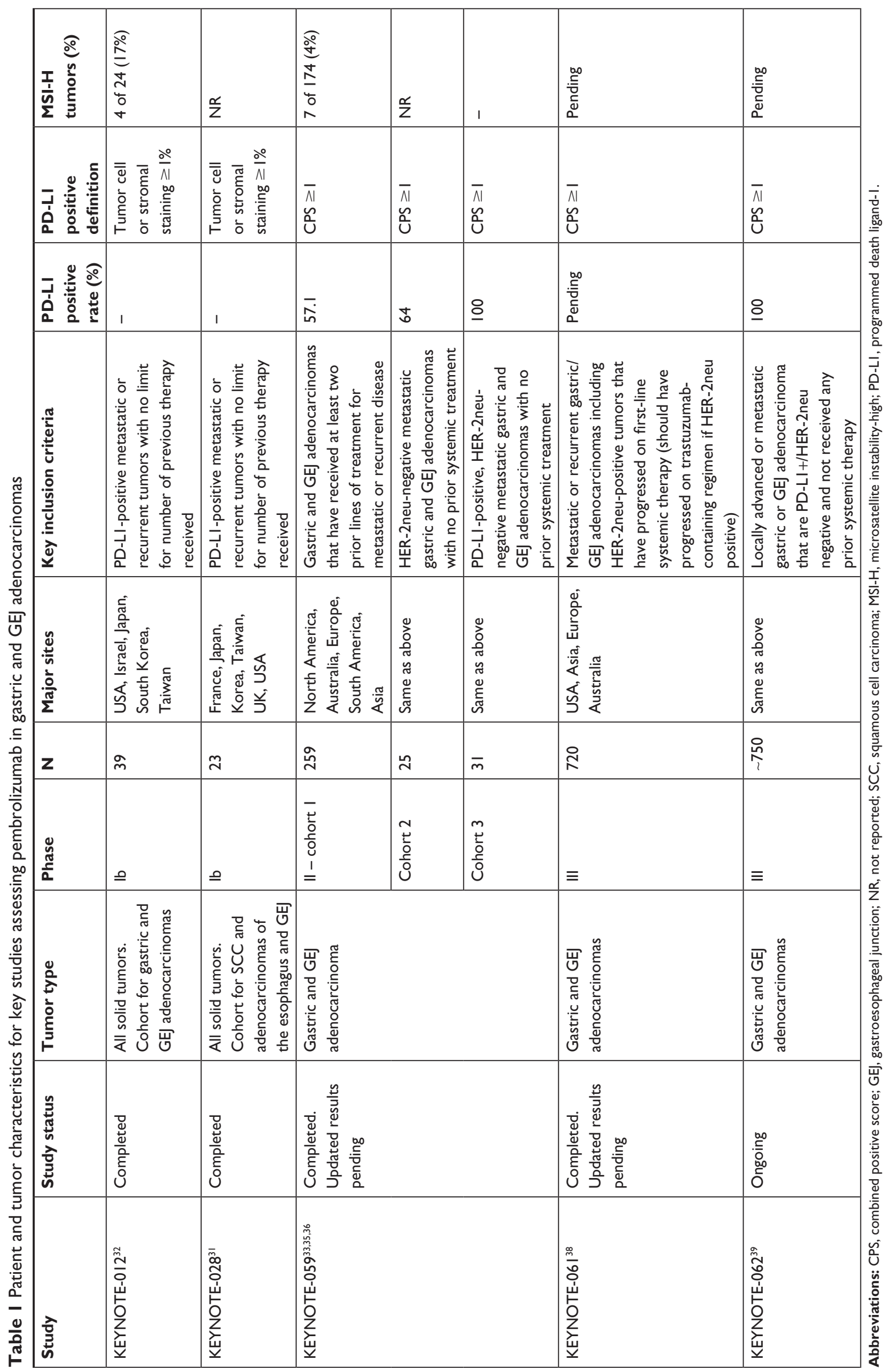




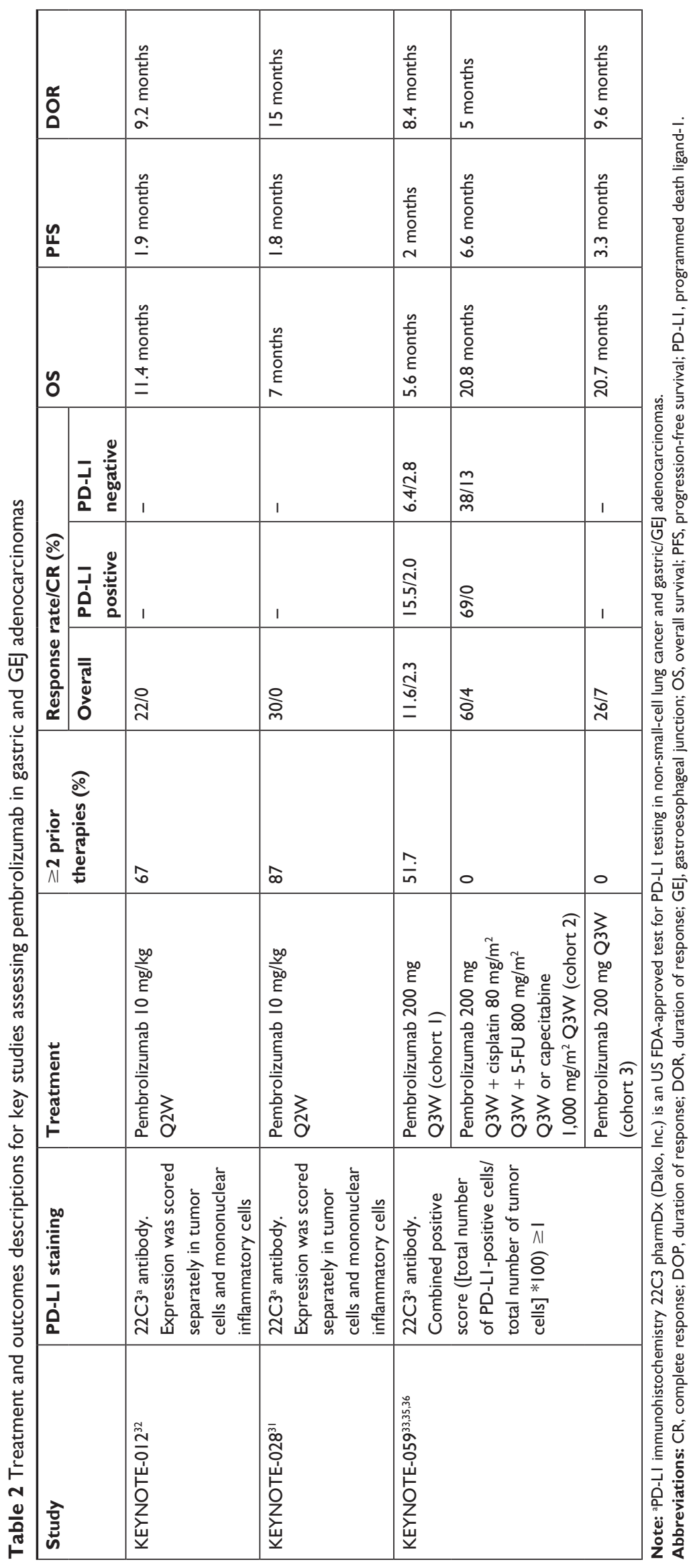


Table 3 Safety and tolerability data for key studies assessing pembrolizumab in gastric and GEJ adenocarcinomas

\begin{tabular}{|c|c|c|c|c|c|c|}
\hline Study & $\begin{array}{l}\text { Dose of } \\
\text { pembrolizumab }\end{array}$ & $\begin{array}{l}\text { Treatment } \\
\text { discontinuation/ } \\
\text { interruptions due to } \\
\text { treatment-related AEs }\end{array}$ & $\begin{array}{l}\text { All treatment- } \\
\text { related AEs }\end{array}$ & $\begin{array}{l}\text { Grade 3/4 } \\
\text { AEs }\end{array}$ & Death & Key AEs \\
\hline KEYNOTE-0I $2^{33}$ & $10 \mathrm{mg} / \mathrm{kg}$ Q2W & None & $26(67 \%)$ & $5(13 \%)$ & None & $\begin{array}{l}\text { Fatigue, decreased } \\
\text { appetite, hypothyroidism } \\
\text { pruritus, arthralgias }\end{array}$ \\
\hline KEYNOTE- $028^{31}$ & 10 mg/kg Q2W & $9 \%$ & $9(39 \%)$ & $\begin{array}{l}4 \text { (9\%). No } \\
\text { Gr4 AEs }\end{array}$ & None & $\begin{array}{l}\text { Rash/generalized rash, } \\
\text { decreased appetite, } \\
\text { decreased lymphocyte } \\
\text { count }\end{array}$ \\
\hline \multirow[t]{3}{*}{ KEYNOTE-05933,35,36 } & \multirow[t]{3}{*}{$200 \mathrm{mg}$ Q3W } & $\mathrm{Cl}-7.7 \%$ & $156(60.2 \%)$ & 46 (I7.8\%) & $2(0.8 \%)$ & $\begin{array}{l}\text { Fatigue, pruritus, } \\
\text { rash, hypothyroidism, } \\
\text { decreased appetite, } \\
\text { anemia, nausea, diarrhea, } \\
\text { arthralgia }\end{array}$ \\
\hline & & $C 2-20 \% *$ & $25(100 \%)$ & $19(76 \%)$ & None & $\begin{array}{l}\text { Neutropenia, stomatitis, } \\
\text { anemia, decreased } \\
\text { appetite, fatigue, HFS, } \\
\text { thrombocytopenia }\end{array}$ \\
\hline & & C3-none & $24(77 \%)$ & $7(23 \%)$ & I (3\%) & $\begin{array}{l}\text { Neutropenia, diffuse } \\
\text { uveal melanocytic } \\
\text { proliferation, colitis, } \\
\text { bile duct obstruction, } \\
\text { dehydration, } \\
\text { hyponatremia, rash }\end{array}$ \\
\hline
\end{tabular}

Note: *Pembrolizumab-related interruptions.

Abbreviations: AEs, adverse events; CI, cohort I; C2, cohort 2; C3, cohort 3; Gr, grade; GEJ, gastroesophageal junction; HFS, hand-foot syndrome.

pembrolizumab to investigator's choice chemotherapy in previously treated urothelial cancer patients showed that pembrolizumab delayed the TTD in QoL scores as compared to chemotherapy (median 3.5 months vs 2.3 months; HR $0.72 ; P=0.004)$. When global health status/QoL scores were compared at baseline and then at 15 weeks, the mean change was $0.69(95 \% \mathrm{CI}-2.40$ to 3.77$)$ with pembrolizumab as compared to -8.36 (95\% CI -11.84 to 4.89$)$ with chemotherapy. ${ }^{44}$ We will have to wait for long-term data from the above trials to make these assessments for gastric and GEJ adenocarcinoma patients. Cost-effectiveness studies derived from the KEYNOTE-045 study show that the cost of pembrolizumab to gain one quality-adjusted life-year is $\$ 122,557$ in the US, which is higher than the cost in other developed countries, but it is considered cost-effective only in the US because of significantly higher threshold for willingness-topay. ${ }^{45}$ Based on the studies, pembrolizumab is also considered as cost-effective, first-line treatment for NSCLC when compared to other chemotherapies that express high levels of PD-L1 with TPS $\geq 50 \% .{ }^{46}$ Such studies are not yet available for gastric or GEJ cancers. While cost-benefit analyses of use of immunotherapy in gastric and GEJ cancers would be valuable information for clinicians, a detailed overview is outside the scope of this article.

\section{Gaps in use of pembrolizumab for gastric and GEJ cancers}

What is the optimum setting for use of pembrolizumab in gastric and GEJ cancers? Does PD-L1 positivity capture all patients who seem to derive the most benefit from this treatment? While pembrolizumab has shown promising results as second-line treatment for gastric and GEJ adenocarcinomas, the KEYNOTE-061 study did not demonstrate an improvement in OS when used in the second-line setting. Although patients with PD-L1 positivity have better ORR than those with PD-L1-negative tumors, responses - and sometimes $\mathrm{CR}$ - are noted in PD-L1-negative patients. While the six-gene interferon $\gamma$ signature used in KEYNOTE012 and KEYNOTE-028 did not predict ORR or PFS, a refined 18-gene T-cell inflamed gene expression profiling score used in KEYNOTE-059 showed better predictive potential. The 18 genes included were CCL5, CD27, CD274 [PD-L1], CD-276 [B7-H3], CD8A, CMKLR1, CXCL9, CXCR6, HLA-DQA1, HLA-DRB1, HLA-E, IDO1, LAG3, 
NKG7, PDCD1LG2 [PD-L2], PSMB10, STAT1, and TGIT. A higher aggregate score was noted in responders than in nonresponders to pembrolizumab. Higher scores were significantly associated with improved responses $(P=0.01)$ as well as improved PFS $(P=0.002)$. Although there was a correlation of this score with PD-L1 expression, it was nonlinear. ${ }^{33}$ Thus, innovative biomarkers are necessary to identify patients that will best benefit from pembrolizumab therapy. The US FDA approved pembrolizumab for the treatment of patients with MSI-H tumors; however, selecting gastric and esophageal cancer patients based on microsatellite status only is not optimal given the low prevalence and the noted response in MSS patients.

\section{Ongoing studies with pembrolizumab}

Several clinical trials are currently ongoing with pembrolizumab in combination with other therapy in various settings in gastric and GEJ cancers. Some of them are outlined in Table 4.

\section{Other immunotherapies and combination treatments}

While several trials are currently ongoing with new checkpoint inhibitors such as durvalumab, atezolizumab, and avelumab, other trials with nivolumab or nivolumab in combination with ipilumumab have shown some promising results.
In the Asian study ATTRACTION-02/ONO-4538-12, patients with metastatic or recurrent gastric or GEJ cancer who had perceived two or more prior lines of treatment were randomized in a $2: 1$ fashion to nivolumab $3 \mathrm{mg} / \mathrm{kg}$ intravenously every 2 weeks or placebo. A total of 493 patients were randomized. The median OS was 5.32 months vs 4.14 months (HR $0.63 ; 95 \%$ CI $0.50-0.78 ; P<0.0001$ ) favoring nivolumab. Subgroup analyses showed that intestinal histology, having two or more sites of metastatic disease, absence of peritoneal and liver metastases, and having received four or more prior lines of treatment were the groups that benefited the most with nivolumab treatment. The ORR was $31 \%$ and OS was superior with nivolumab irrespective of PD-L1 status. ${ }^{47}$

In another study of nivolumab in combination with chemotherapy for treatment-naïve metastatic HER-2neunegative gastric/GEJ cancers, 40 patients were randomized to nivolumab $360 \mathrm{mg}$ every 3 weeks plus S-1/oxaliplatin or nivolumab plus capecitabine/oxaliplatin. Both treatments were well tolerated. All patients developed treatment-related AEs. No deaths were reported. The ORR was $68.4 \%$, with 10 patients achieving $\mathrm{CR} .{ }^{48}$

In the CheckMate 032 study, patients with metastatic esophageal, GEJ, or gastric cancers who had received one or more prior lines of treatment for metastatic disease were randomized $1: 1: 1$ to nivolumab $3 \mathrm{mg} / \mathrm{kg}$ intravenously Q2W (N3) vs nivolumab $1 \mathrm{mg} / \mathrm{kg}$ + ipilimumab $3 \mathrm{mg} / \mathrm{kg}$

Table 4 Ongoing trials in gastric and gastroesophageal junction cancers with pembrolizumab

\begin{tabular}{|l|l|l|l|l|l|l|}
\hline $\begin{array}{l}\text { Study name/ } \\
\text { NCT }\end{array}$ & Phase & $\begin{array}{l}\text { Type of } \\
\text { treatment }\end{array}$ & Treatment regimen & Expected N & Study site & $\begin{array}{l}\text { Primary } \\
\text { endpoints }\end{array}$ \\
\hline Neoadjuvant/adjuvant/perioperative trials & Perioperative & $\begin{array}{l}\text { Pembrolizumab + investigator's } \\
\text { choice chemotherapy 3 cycles } \\
\text { preoperatively and 3 cycles } \\
\text { postoperatively. One additional } \\
\text { cycle of pembrolizumab will } \\
\text { be given preoperatively. Post- } \\
\text { operatively patients will complete } \\
\text { I2 months of maintenance therapy }\end{array}$ & 40 & USA & month DFS \\
\hline 0318162 & II & Neoadjuvant & $\begin{array}{l}\text { Pembrolizumab } \times 3 \text { doses pre- } \\
\text { operatively with concurrent } \\
\text { chemoradiation with carboplatin/ } \\
\text { paclitaxel. Three additional doses } \\
\text { of adjuvant pembrolizumab }\end{array}$ & 38 & USA & PCR rate \\
\hline PROCEED) & II & Perioperative & $\begin{array}{l}\text { Pembrolizumab } \times 3 \text { doses }+ \\
\text { mFOLFOX } \times 4 \text { doses preoperatively } \\
\text { and pembrolizumab } \times \text { I2 } \\
\text { doses + mFOLFOX } \times 4 \text { doses } \\
\text { postoperatively }\end{array}$ & 40 & USA \\
\hline 0348667 & II & PCR rate, AEs & \\
\hline
\end{tabular}

(Continued) 
Table 4 (Continued)

\begin{tabular}{|c|c|c|c|c|c|c|}
\hline $\begin{array}{l}\text { Study namel } \\
\text { NCT }\end{array}$ & Phase & $\begin{array}{l}\text { Type of } \\
\text { treatment }\end{array}$ & Treatment regimen & Expected $\mathbf{N}$ & Study site & $\begin{array}{l}\text { Primary } \\
\text { endpoints }\end{array}$ \\
\hline $\begin{array}{l}0322 \mid 426 \\
\text { (KEYNOTE-585) }\end{array}$ & III & Perioperative & $\begin{array}{l}\text { Cohort I: pembrolizumab }+5 \text {-FU/ } \\
\text { cisplatin or capecitabine/cisplatin } \times \\
3 \text { doses preoperatively and up to } \\
\text { I } 4 \text { doses postoperatively. } \\
\text { Cohort I comparator: } \\
\text { placebo }+5 \text {-FU/cisplatin or } \\
\text { capecitabine/cisplatin } \times 3 \text { doses } \\
\text { preoperatively and up to I4 doses } \\
\text { postoperatively. } \\
\text { Cohort } 2 \text { : pembrolizumab } \times 3 \\
\text { doses }+ \text { FLOT } \times 4 \text { administrations } \\
\text { preoperatively. Pembrolizumab } \times \\
\text { up to II cycles }+ \text { FLOT } \times 4 \\
\text { administrations postoperatively. } \\
\text { Cohort } 2 \text { comparator: placebo } \times 3 \\
\text { doses }+ \text { FLOT } \times 4 \text { administrations } \\
\text { preoperatively. Placebo }+ \text { FLOT } \times \\
4 \text { administrations postoperatively. }\end{array}$ & 860 & $\begin{array}{l}\text { North America, } \\
\text { South America, } \\
\text { Europe, Russia, } \\
\text { Asia }\end{array}$ & $\begin{array}{l}\text { OS, EFS, pCR } \\
\text { rate, AEs }\end{array}$ \\
\hline 03257163 & II & $\begin{array}{l}\text { Perioperative in } \\
\text { MSI-H or EBV- } \\
\text { positive operable } \\
\text { gastric cancer }\end{array}$ & $\begin{array}{l}\text { Pembrolizumab } \times 2 \text { doses } \rightarrow \\
\text { surgery } \rightarrow \text { pembrolizumab }+ \\
\text { capecitabine } \times 5 \text { doses } \rightarrow \\
\text { pembrolizumab } \times \text { up to II doses } \\
\text { (RT starts at around fourth dose } \\
\text { for } 5 \text { weeks) }\end{array}$ & 40 & USA & RFS \\
\hline 02730546 & $\mathrm{lb} / \mathrm{ll}$ & $\begin{array}{l}\text { Neoadjuvant and } \\
\text { adjuvant therapy } \\
\text { for operable GEJ } \\
\text { and gastric cardia } \\
\text { adenocarcinomas }\end{array}$ & $\begin{array}{l}\text { Pembrolizumab plus concurrent } \\
\text { chemoradiation with carboplatin/ } \\
\text { paclitaxel preoperatively. } \\
\text { Pembrolizumab as adjuvant } \\
\text { treatment }\end{array}$ & 68 & USA & $\mathrm{PCR}$ rate, $\mathrm{PFS}$ \\
\hline \multicolumn{7}{|c|}{ Metastatic trials - first-line } \\
\hline $\begin{array}{l}02494583 \\
\text { (KEYNOTE-062) }\end{array}$ & III & $\begin{array}{l}\text { First-line metastatic } \\
\text { (HER-2neu } \\
\text { negative, PD-LI } \\
\text { positive) }\end{array}$ & $\begin{array}{l}\text { Pembro vs pembro }+5-\mathrm{FU}+ \\
\text { cisplatin vs placebo }+5-\mathrm{FU}+ \\
\text { cisplatin }\end{array}$ & 764 & Worldwide & PFS, OS \\
\hline $\begin{array}{l}03342937 \\
\text { (KeyLargo) }\end{array}$ & II & First-line metastatic & $\begin{array}{l}\text { Pembrolizumab + oxaliplatin + } \\
\text { capecitabine }\end{array}$ & 50 & USA & PFS \\
\hline 02563548 & $\mathrm{I}$ & $\begin{array}{l}\text { Hyaluronan-high } \\
\text { NSCLC and gastric } \\
\text { cancer. Not have } \\
\text { received more than } \\
\text { two prior lines } \\
\text { of treatment for } \\
\text { metastatic gastric } \\
\text { cancer }\end{array}$ & PEGPH20 plus pembrolizumab & $\begin{array}{l}81 \text { (including } \\
\text { NSCLC) }\end{array}$ & USA & ORR \\
\hline 02830594 & II & $\begin{array}{l}\text { Metastatic } \\
\text { esophageal, GEJ and } \\
\text { gastric cancers with } \\
\text { no limit on number } \\
\text { of prior treatments } \\
\text { received }\end{array}$ & $\begin{array}{l}\text { Palliative RT for } 35 \text { fractions with } \\
\text { pembrolizumab }\end{array}$ & 14 & USA & $\begin{array}{l}\text { Comparison } \\
\text { of molecular } \\
\text { biomarkers } \\
\text { and disease } \\
\text { outcomes }\end{array}$ \\
\hline 02954536 & II & $\begin{array}{l}\text { First-line metastatic } \\
\text { for HER-2neu } \\
\text { positive esophageal, } \\
\text { GEJ, or gastric } \\
\text { adenocarcinoma }\end{array}$ & $\begin{array}{l}\text { Pembrolizumab + trastuzumab + } \\
\text { capecitabine/cisplatin }\end{array}$ & 37 & USA & PFS \\
\hline
\end{tabular}


Table 4 (Continued)

\begin{tabular}{|c|c|c|c|c|c|c|}
\hline $\begin{array}{l}\text { Study namel } \\
\text { NCT }\end{array}$ & Phase & $\begin{array}{l}\text { Type of } \\
\text { treatment }\end{array}$ & Treatment regimen & Expected $\mathbf{N}$ & Study site & $\begin{array}{l}\text { Primary } \\
\text { endpoints }\end{array}$ \\
\hline \multicolumn{7}{|c|}{ Metastatic trials - post first-line } \\
\hline $\begin{array}{l}02370498 \\
\text { (KEYNOTE-06I) }\end{array}$ & III & $\begin{array}{l}\text { Post first-line in } \\
\text { metastatic gastric/ } \\
\text { GEJ cancers } \\
\text { (subsequently } \\
\text { limited to PD-LI- } \\
\text { positive tumors } \\
\text { only) }\end{array}$ & Pembrolizumab vs paclitaxel & 592 & Worldwide & PFS, OS \\
\hline 02689284 & $1 / I I$ & $\begin{array}{l}\text { Post first-line in } \\
\text { HER-2neu-positive } \\
\text { metastatic gastric/ } \\
\text { GEJ cancers }\end{array}$ & Pembrolizumab and margetuximab & 72 & USA, Asia & $\begin{array}{l}\text { RP2D, DOR, } \\
\text { ORR }\end{array}$ \\
\hline $\begin{array}{l}3019588 \\
(\text { KEYNOTE-063) }\end{array}$ & III & $\begin{array}{l}\text { Post first-line in } \\
\text { Asian patients with } \\
\text { metastatic gastric/ } \\
\text { GEJ cancers }\end{array}$ & Pembrolizumab vs paclitaxel & 360 & Asia & OS, PFS \\
\hline 03196232 & II & $\begin{array}{l}\text { Post first-line } \\
\text { metastatic } \\
\text { esophageal, gastric, } \\
\text { and GEJ cancers }\end{array}$ & Epacadostat plus pembrolizumab & 30 & USA & PFS \\
\hline $034 \mid 3397$ & II & $\begin{array}{l}\text { Post first-line } \\
\text { metastatic or } \\
\text { recurrent gastric/ } \\
\text { GEJ cancer }\end{array}$ & Lenvatinib plus pembrolizumab & 29 & USA & ORR \\
\hline 03395847 & I & $\begin{array}{l}\text { Post first-line } \\
\text { metastatic GEJ } \\
\text { cancer }\end{array}$ & $\begin{array}{l}\text { Pembrolizumab monotherapy or } \\
\text { pembrolizumb + ramucirumab }\end{array}$ & 30 & USA & ORR \\
\hline
\end{tabular}

Abbreviations: AEs, adverse events; DFS, disease-free survival; DOR, duration of response; EFS, event-free survival; FLOT-5-FU, docetaxel, leucovorin, oxaliplatin; GEJ, gastroesophageal junction; ORR, overall response rate; PEGPH20, pegylated recombinant human hyluronidase; PFS, progression-free survival; RFS, relapse-free survival; RP2D, recommended Phase II dose; RT, radiation therapy; mFOLFOX-5-FU, modified 5-fluorouracil (5-FU) leucovorin (LV), and Eloxatin (oxaliplatin) leucovorin, oxaliplatin; $\mathrm{PCR}$, pathological complete response.

Q3W $\times$ four doses followed by nivolumab $3 \mathrm{mg} / \mathrm{kg}$ Q2W $(\mathrm{N} 1+\mathrm{I} 3)$ vs nivolumab $3 \mathrm{mg} / \mathrm{kg}+$ ipilimumab $1 \mathrm{mg} / \mathrm{kg}$ Q3 $\mathrm{W} \times$ four doses followed by nivolumab $3 \mathrm{mg} / \mathrm{kg}$ Q2W $(\mathrm{N} 3+\mathrm{I} 1)$. Seventy nine percent patients had received two or more prior therapies and $24 \%$ had PD-L1-positive tumors. The ORRs was $12 \%(\mathrm{~N} 3), 24 \%(\mathrm{~N} 1+\mathrm{I} 3)$, and $8 \%(\mathrm{~N} 3+\mathrm{I} 1)$. The ORRs were $19 \%(\mathrm{~N} 3), 40 \%(\mathrm{~N} 1+\mathrm{I} 3), 23 \%(\mathrm{~N} 3+\mathrm{I} 1)$ and $12 \%(\mathrm{~N} 3), 22 \%(\mathrm{~N} 1+\mathrm{I} 3), 0 \%(\mathrm{~N} 3+\mathrm{I} 1)$ in PD-L1-positive and PD-L1-negative tumors, respectively. Median OS was 6.2 months (95\% CI 3.4-12.4 months) in N3, 6.9 months (95\% CI 3.7-11.5 months) in $\mathrm{N} 1+\mathrm{I} 3$, and 4.8 months (95\% CI 3.0-8.4 months) in N3 + I1. Grade 3-4 AEs were noted in more than $10 \%$ of each arm. The combination arm showed durable responses in heavily pretreated gastric and GEJ cancers. ${ }^{49}$

\section{Future directions}

Checkpoint inhibitors have revolutionized the way we now treat advanced cancers. Several clinical studies have shown some promising response rates even in heavily pretreated population of metastatic gastric and GEJ cancers. However, there yet remains a lack of biomarkers or combination of biomarkers that can help identify patients who will respond to immunotherapy and spare them from serious AEs. It is unclear why pembrolizumab shows the best response rates in third-line setting, while it failed to improve OS when used as a second-line treatment. Ongoing trials will guide us on whether combination treatment with chemotherapy, tyrosine kinase inhibitors, other monoclonal antibodies, or radiation therapy will improve response rates in advanced gastric and GEJ cancers. In addition to pembrolizumab, there are other checkpoint inhibitors that are currently being tested and likely to be approved soon for gastric and GEJ cancers.

\section{Disclosure}

The authors report no conflicts of interest in this work.

\section{References}

1. Cancer Incidence and Mortality Worldwide: IARC CancerBase No. 11. International Agency for Research on Cancer; 2013; 2012. Available from: http://globocan.iarc.fr. Accessed May 26, 2018. 
2. National Cancer Institute. SEER Cancer Statistics Review, 1975-2015. Available from: https://seer.cancer.gov/csr/1975_2015/. Accessed May 26, 2018.

3. Ajani JA, Lee J, Sano T, Janjigian YY, Fan D, Song S. Gastric adenocarcinoma. Nat Rev Dis Primers. 2017;3:17036.

4. Buas MF, Vaughan TL. Epidemiology and risk factors for gastroesophageal junction tumors: understanding the rising incidence of this disease. Semin Radiat Oncol. 2013;23(1):3-9.

5. Jin Z, Yoon HH. The promise of PD-1 inhibitors in gastro-esophageal cancers: microsatellite instability vs. PD-L1. J Gastrointest Oncol. 2016;7(5):771-788.

6. Al-Batran SE, Hartmann JT, Probst S, et al. Phase III trial in metastatic gastroesophageal adenocarcinoma with fluorouracil, leucovorin plus either oxaliplatin or cisplatin: a study of the Arbeitsgemeinschaft Internistische Onkologie. J Clin Oncol. 2008;26(9): $1435-1442$.

7. Cunningham D, Starling N, Rao S, et al. Capecitabine and oxaliplatin for advanced esophagogastric cancer. N Engl J Med. 2008;358(1):36-46.

8. van Cutsem E, Moiseyenko VM, Tjulandin S, et al. Phase III study of docetaxel and cisplatin plus fluorouracil compared with cisplatin and fluorouracil as first-line therapy for advanced gastric cancer: a report of the V325 Study Group. J Clin Oncol. 2006;24(31):4991-4997.

9. Bang YJ, van Cutsem E, Feyereislova A, et al. Trastuzumab in combination with chemotherapy versus chemotherapy alone for treatment of HER2-positive advanced gastric or gastro-oesophageal junction cancer (ToGA): a phase 3, open-label, randomised controlled trial. Lancet. 2010;376(9742):687-697.

10. Fuchs CS, Tomasek J, Yong CJ, et al. Ramucirumab monotherapy for previously treated advanced gastric or gastro-oesophageal junction adenocarcinoma (REGARD): an international, randomised, multicentre, placebo-controlled, phase 3 trial. Lancet. 2014;383(9911):31-39.

11. Wilke H, Muro K, van Cutsem E, et al. Ramucirumab plus paclitaxel versus placebo plus paclitaxel in patients with previously treated advanced gastric or gastro-oesophageal junction adenocarcinoma (RAINBOW): a double-blind, randomised phase 3 trial. Lancet Oncol. 2014;15(11):1224-1235.

12. Catenacci DVT, Tebbutt NC, Davidenko I, et al. Rilotumumab plus epirubicin, cisplatin, and capecitabine as first-line therapy in advanced MET-positive gastric or gastro-oesophageal junction cancer (RILOMET-1): a randomised, double-blind, placebo-controlled, phase 3 trial. Lancet Oncol. 2017;18(11):1467-1482.

13. Hecht JR, Bang YJ, Qin SK, et al. Lapatinib in Combination With Capecitabine Plus Oxaliplatin in Human Epidermal Growth Factor Receptor 2-Positive Advanced or Metastatic Gastric, Esophageal, or Gastroesophageal Adenocarcinoma: TRIO-013/LOGiC - A Randomized Phase III Trial. J Clin Oncol. 2016;34(5):443-451.

14. Lordick F, Kang YK, Chung HC, et al. Capecitabine and cisplatin with or without cetuximab for patients with previously untreated advanced gastric cancer (EXPAND): a randomised, open-label phase 3 trial. Lancet Oncol. 2013;14(6):490-499.

15. Ohtsu A, Shah MA, van Cutsem E, et al. Bevacizumab in combination with chemotherapy as first-line therapy in advanced gastric cancer: a randomized, double-blind, placebo-controlled phase III study. J Clin Oncol. 2011;29(30):3968-3976.

16. Satoh T, Xu RH, Chung HC, et al. Lapatinib plus paclitaxel versus paclitaxel alone in the second-line treatment of HER2-amplified advanced gastric cancer in Asian populations: TyTAN - a randomized, phase III study. J Clin Oncol. 2014;32(19):2039-2049.

17. Tabernero J, Hoff PM, Shen L, et al. 616OPertuzumab (P) + trastuzumab $(\mathrm{H})+$ chemotherapy $(\mathrm{CT})$ for HER2-positive metastatic gastric or gastro-oesophageal junction cancer (mGC/GEJC): Final analysis of a Phase III study (JACOB). Annals of Oncology. 2017;28(suppl_5): v209-v268.

18. Thuss-Patience PC, Shah MA, Ohtsu A, et al. Trastuzumab emtansine versus taxane use for previously treated HER2-positive locally advanced or metastatic gastric or gastro-oesophageal junction adenocarcinoma (GATSBY): an international randomised, open-label, adaptive, phase 2/3 study. Lancet Oncol. 2017;18(5):640-653.
19. Waddell T, Chau I, Cunningham D, et al. Epirubicin, oxaliplatin, and capecitabine with or without panitumumab for patients with previously untreated advanced oesophagogastric cancer (REAL3): a randomised, open-label phase 3 trial. Lancet Oncol. 2013;14(6):481-489.

20. Cancer Genome Atlas Research N. Comprehensive molecular characterization of gastric adenocarcinoma. Nature. 2014;513:202-209.

21. Pembrolizumab [package insert]. Whitehouse Station: Merck Sharp \& Dohme Corp, NJ. 2017.

22. Fuchs CS, Doi T, Jang RW, et al. Safety and Efficacy of Pembrolizumab Monotherapy in Patients With Previously Treated Advanced Gastric and Gastroesophageal Junction Cancer: Phase 2 Clinical KEYNOTE-059 Trial. JAMA Oncol. 2018;4(5):e180013.

23. Wang M, Busuttil RA, Pattison S, Neeson PJ, Boussioutas A. Immunological battlefield in gastric cancer and role of immunotherapies. World J Gastroenterol. 2016;22(28):6373-6384.

24. Kelly RJ. Immunotherapy for Esophageal and Gastric Cancer. Am Soc Clin Oncol Educ Book. 2017;37:292-300.

25. Ock CY, Hwang JE, Keam B, et al. Genomic landscape associated with potential response to anti-CTLA-4 treatment in cancers. Nat Commun. 2017;8(1):1050.

26. Toor SM, Syed Khaja AS, Alkurd I, Elkord E. In-vitro effect of pembrolizumab on different T regulatory cell subsets. Clin Exp Immunol. 2018;191(2):189-197.

27. Zhao L, Ren TH, Wang DD. Clinical pharmacology considerations in biologics development. Acta Pharmacol Sin. 2012;33(11):1339-1347.

28. Freshwater T, Kondic A, Ahamadi M, et al. Evaluation of dosing strategy for pembrolizumab for oncology indications. JImmunother Cancer. 2017;5:43.

29. Le DT, Durham JN, Smith KN, et al. Mismatch repair deficiency predicts response of solid tumors to PD-1 blockade. Science. 2017; 357(6349):409-413.

30. Le DT, Uram JN, Wang H, et al. PD-1 Blockade in Tumors with MismatchRepair Deficiency. N Engl J Med. 2015;372(26):2509-2520.

31. Doi T, Piha-Paul SA, Jalal SI, et al. Safety and Antitumor Activity of the Anti-Programmed Death-1 Antibody Pembrolizumab in Patients With Advanced Esophageal Carcinoma. J Clin Oncol. 2018;36(1):61-67.

32. Muro K, Chung HC, Shankaran V, et al. Pembrolizumab for patients with PD-L1-positive advanced gastric cancer (KEYNOTE-012): a multicentre, open-label, phase 1b trial. Lancet Oncol. 2016;17(6):717-726.

33. Fuchs CS, Doi T, Jang RW, et al. Safety and Efficacy of Pembrolizumab Monotherapy in Patients With Previously Treated Advanced Gastric and Gastroesophageal Junction Cancer: Phase 2 Clinical KEYNOTE-059 Trial. JAMA Oncol. 2018;4(5):e180013.

34. Food And Drug Administration. FDA grants accelerated approval to pembrolizumab for advanced gastric cancer; 2017. Available from: https://www.fda.gov/Drugs/InformationOnDrugs/ApprovedDrugs/ ucm577093.htm. Accessed May 27, 2018.

35. Bang Y-J, Muro K, Fuchs CS, et al. KEYNOTE-059 cohort 2: Safety and efficacy of pembrolizumab (pembro) plus 5-fluorouracil (5-FU) and cisplatin for first-line (1L) treatment of advanced gastric cancer. Journal of Clinical Oncology. 2017;35(15_suppl):4012.

36. Catenacci DV, Wainberg Z, Fuchs CS. KEYNOTE-059 cohort 3: safety and efficacy of pembrolizumab monotherapy for first-line treatment of patients (pts) with PD-L1-positive advanced gastric/gastroesophageal (G/GEJ) cancer. Annals of Oncology. 2017;28:153.

37. Updated Data in KEYNOTE-061: Pembrolizumab in Previously Treated Gastric or Gastroesophageal Junction Adenocarcinoma. The ASCO Post; 2017. Available from: http://www.ascopost.com/News/58377. Accessed May 27, 2018.

38. Ohtsu A, Tabernero J, Bang Y-J, et al. Pembrolizumab versus paclitaxel as second-line therapy for advanced gastric or gastroesophageal junction (GEJ) adenocarcinoma: Phase 3 KEYNOTE-061 study. Journal of Clinical Oncology. 2016;34(15_suppl):TPS4137.

39. Tabernero J, Bang Y-J, Fuchs CS, et al. KEYNOTE-062: Phase III study of pembrolizumab (MK-3475) alone or in combination with chemotherapy versus chemotherapy alone as first-line therapy for advanced gastric or gastroesophageal junction (GEJ) adenocarcinoma. Journal of Clinical Oncology. 2016;34(4_suppl):TPS185. 
40. Bellmunt J, de Wit R, Vaughn DJ, et al. Pembrolizumab as Second-Line Therapy for Advanced Urothelial Carcinoma. NEnglJMed. 2017;376(11): 1015-1026.

41. Garon EB, Rizvi NA, Hui R, et al. Pembrolizumab for the treatment of non-small-cell lung cancer. N Engl J Med. 2015;372(21): 2018-2028.

42. Robert C, Schachter J, Long GV, et al. Pembrolizumab versus Ipilimumab in Advanced Melanoma. N Engl J Med. 2015;372(26):2521-2532.

43. Brahmer JR, Rodríguez-Abreu D, Robinson AG, et al. Health-related quality-of-life results for pembrolizumab versus chemotherapy in advanced, PD-L1-positive NSCLC (KEYNOTE-024): a multicentre, international, randomised, open-label phase 3 trial. Lancet Oncol. 2017;18(12):1600-1609.

44. Vaughn DJ, Bellmunt J, Fradet Y, et al. Health-Related Quality-of-Life Analysis From KEYNOTE-045: A Phase III Study of Pembrolizumab Versus Chemotherapy for Previously Treated Advanced Urothelial Cancer. J Clin Oncol. 2018;36(16):1579-1587.

45. Sarfaty M, Hall PS, Chan KKW, et al. Cost-effectiveness of Pembrolizumab in Second-line Advanced Bladder Cancer. Eur Urol. 2018; 74(1):57-62.
46. Huang M, Lou Y, Pellissier J, et al. Cost Effectiveness of Pembrolizumab vs. Standard-of-Care Chemotherapy as First-Line Treatment for Metastatic NSCLC that Expresses High Levels of PD-L1 in the United States. Pharmacoeconomics. 2017;35(8):831-844.

47. Kang Y-K, Satoh T, Ryu M-H, et al. Nivolumab (ONO-4538/BMS936558) as salvage treatment after second or later-line chemotherapy for advanced gastric or gastro-esophageal junction cancer (AGC): A double-blinded, randomized, phase III trial. Journal of Clinical Oncology. 2017;35(4_suppl):2.

48. Kang Y-K, Kato K, Chung HC, et al. 671PInterim safety and clinical activity of nivolumab (Nivo) in combination with S-1/capecitabine plus oxaliplatin in patients (pts) with previously untreated unresectable advanced or recurrent gastric/gastroesophageal junction $(\mathrm{G} / \mathrm{GEJ})$ cancer: part 1 study of ATTRACTION-04 (ONO-4538-37). Annals of Oncology. 2017;28(suppl_5):mdx369.055.

49. Janjigian YY, Ott PA, Calvo E, et al. Nivolumab \pm ipilimumab in pts with advanced (adv)/metastatic chemotherapy-refractory (CTx-R) gastric (G), esophageal (E), or gastroesophageal junction (GEJ) cancer: CheckMate 032 study. Journal of Clinical Oncology. 2017; 35(15_suppl):4014.

\section{Publish your work in this journal}

OncoTargets and Therapy is an international, peer-reviewed, open access journal focusing on the pathological basis of all cancers, potential targets for therapy and treatment protocols employed to improve the management of cancer patients. The journal also focuses on the impact of management programs and new therapeutic agents and protocols on

\section{Dovepress}

patient perspectives such as quality of life, adherence and satisfaction. The manuscript management system is completely online and includes a very quick and fair peer-review system, which is all easy to use. Visit http://www.dovepress.com/testimonials.php to read real quotes from published authors.

\footnotetext{
Submit your manuscript here: http://www.dovepress.com/oncotargets-and-therapy-journal
} 